MESSINEO Cristina, Arte verbal qom: consejos, rogativas y relatos de El Espinillo (Chaco)

Textos y comentarios de Mauricio Maidana, editorial Rumbo Sur/ ethnographica, Buenos Aires, 2014, 208 p., mapas, fotos en blanco y negro, tablas.

\title{
Emilio Robledo
}

\section{(2) OpenEdition}

Journals

Edición electrónica

URL: https://journals.openedition.org/jsa/14779

DOI: 10.4000/jsa. 14779

ISSN: 1957-7842

Editor

Société des américanistes

Edición impresa

Fecha de publicación: 31 diciembre 2016

Paginación: 247-250

ISSN: 0037-9174

\section{Referencia electrónica}

Emilio Robledo, «MEssineo Cristina, Arte verbal qom: consejos, rogativas y relatos de El Espinillo (Chaco)», Journal de la Société des américanistes [En línea], 102-2 | 2016, Publicado el 26 enero 2017, consultado el 03 septiembre 2022. URL: http://journals.openedition.org/jsa/14779 ; DOI: https://doi.org/10.4000/ jsa. 14779

Este documento fue generado automáticamente el 3 septiembre 2022.

All rights reserved 


\section{MESSINEO Cristina, Arte verbal qom: consejos, rogativas y relatos de El Espinillo (Chaco)}

Textos y comentarios de Mauricio Maidana, editorial Rumbo Sur/ ethnographica, Buenos Aires, 2014, 208 p., mapas, fotos en blanco y negro, tablas.

\section{Emilio Robledo}

\section{REFERENCIA}

MESSINEO Cristina, Arte verbal qom: consejos, rogativas y relatos de El Espinillo (Chaco), Textos y comentarios de Mauricio Maidana, editorial Rumbo Sur/ethnographica, Buenos Aires, 2014, 208 p., mapas, fotos en blanco y negro, tablas.

1 En la presente obra, publicada en español con textos bilingües qom-español, la lingüista Cristina Messineo, especialista en lengua toba quien trabaja en el Gran Chaco desde hace más de tres décadas, dialoga con textos y notas etnográficas producidas por Mauricio Maidana, hablante nativo del qom (toba), originario de la localidad de El Espinillo (provincia de Chaco). A ambos los antecede una larga trayectoria de trabajo colaborativo en el estudio, revitalización y difusión de la lengua qom. Esta obra se inserta en la propuesta editorial de la colección ethnographica (Buenos Aires, Rumbo Sur) dedicada a publicar investigaciones, muchas de ellas colaborativas, en las que especialistas de diferentes disciplinas y autores indígenas entretejen sus reflexiones y sus voces. Arte verbal qom se propone aportar al registro y estudio de los géneros del habla qom, que articula de manera original y fructífera el análisis lingüístico con la documentación etnográfica. Los materiales y análisis expuestos colman así los vacíos que suelen dejar estudios basados en metodologías ya ajustadas a la lingüística ya a la etnografía.

Los géneros discursivos abordados en el libro son, por un lado, los "consejos" (nqataxacpi) y las « rogativas» (natamnaxacpi), mediante las cuales se trata de « afectar» 
a las personas a quienes son dirigidos; por otro lado, se considera las narraciones - género no designado por un término lexicalizado - que se caracterizan por transmitir la memoria de personajes, hechos del pasado o lugares que fueron y son habitados por los qom (en este caso del noroeste de la provincia de Chaco y del centro formoseño). Según la autora y otros estudiosos (Wright 1990 y 2008; Ceriani Cernadas 2008), estos géneros de discursos no forman parte de un patrimonio oral ya desvaneciendo, sino que juegan un papel importante en las relaciones cotidianas contemporáneas del grupo. Con Arte verbal qom, los interesados por la región chaqueña cuentan así con un novedoso material lingüístico, cuya riqueza se proyecta, notablemente, hacia los temas más salientes de la etnografía regional: parentesco y convivialidad, toponimia e historia territorializada, relaciones interétnicas, cosmología y seres no-humanos, entre otros.

3 En la Introducción, es donde mayor presencia tiene la voz de la autora. Guía al lector para que pueda familiarizarse tanto con el contexto geográfico e histórico del Gran Chaco y del pueblo qom, como con las características generales de su lengua. Asimismo, los aspectos propiamente lingüísticos (fonológía y morfosintáctica) son expuestos sin perder el trasfondo socio-cultural de la lengua. Los discursos presentados luego son fragmentos verbales que testimonian la concepción nativa de la lengua. « Las palabras de los qom» (como sería más propio traducir la noción qom l'aqtaqa, que por comodidad suele traducirse como « la lengua qom ») no se reducen a un soporte de comunicación por el que se transmiten ideas e historias, sino que ellas mismas «tienen poder» (huo'oi da la'añaxac). Esto es, las palabras dichas por el líder, el predicador, el chamán, el padre o el rogante en general «conllevan intención y voluntad, y ejercen influencia sobre las personas, los objetos y los eventos» (p. 30). Esta verdadera continuidad de las relaciones sociales por medio del verbo, que no siempre se comprende cabalmente, es lo que Cristina Messineo decide explorar mediante la noción de « arte verbal ». Con esta noción se subraya la dimensión pragmática de prácticas verbales que tienen lugar en situaciones comunicativas reconocidas por los qom y que involucran recursos lingüísticos y no lingüísticos (turnos de habla, tono, prosodia, silencios, etc.) específicos. Es por ello que la performance es central, según la autora, para el estudio y comprensión de estos repertorios.

Las dos partes de la obra que siguen la introducción están compuestas, en su totalidad, por los textos y comentarios de Mauricio Maidana, con breves introducciones y notas aclaratorias al pie de página escritas por Cristina Messineo. A partir de aquí cobra protagonismo la voz qom en los géneros orales presentados en su lengua de origen, seguidos de su traducción al español y encabezados por un título consignado por su autor. La primera parte, destinada a exponer el " arte de la oratoria ", está conformada por un primer capítulo que aborda el género de los consejos y un segundo el género de las rogativas. La segunda parte, dedicada al "arte de narrar ", incluye capítulos con relatos sobre historias de lugares, de caciques y chamanes, de la iglesia de El Espinillo, de la música así como relatos de humor. Quizás pueda llamar la atención la falta de un capítulo dedicado a las conclusiones. Esta ausencia, sin embargo, forma parte de una decisión de la autora que busca menguar su propia voz en provecho del protagonismo de la voz qom contenida en los relatos.

5 Las cualidades intrínsecas del material presentado (su novedad y valor socio-cultural) están realzadas por una exposición que siempre pone en contacto estrecho la lengua qom con la traducción español. Los textos originales son desglosados en oraciones que forman, en sí mismas, unidades de sentido y la traducción de cada uno de estos 
fragmentos sigue en la línea inmediata. Cada relato constituye así una unidad textual bilinguë. Esto no es menor ya que permite a los conocedores de la lengua qom revisar el sentido y la interpretación hecha en cada parte de la traducción. Esta particularidad de la traducción se convierte en un aporte de la obra que contrasta con los trabajos que ofrecen textos bilingües con traducciones globales en las que el lector no puede rastrear las decisiones del traductor. Es de destacar, además, que los textos que aquí se tratan tienen sus fuentes (lingüísticas y socio-culturales) en las relaciones y los puntos de vista qom. No se trata de textos en español traducidos a la lengua indígena con el objeto de ilustrar el contexto etnográfico. En esto radica también la riqueza e importancia de los materiales editados.

Para los que trabajan en el Gran Chaco no pasa desapercibido el papel destacado tanto de los consejos en las conversaciones domésticas como de los pedidos u oraciones, en múltiples contextos. Por el poder que contienen, las palabras despiertan tal expectativa en el rogante que el fracaso en obtener lo que pide suele sumirlo en un profundo desahucio. Tampoco se ignora que los personajes y lugares recordados en estos textos poseen una relevancia social que es patente hoy en día. Meguesoxochi, Dompae, Netoqui, por ejemplo, son personas cuya voz y andanzas aún aparecen en las conversaciones de la gente, a veces entre risas, a veces entre lamentos. Huaca llegueta, Misión Emanuel, El Espinillo, Taxaqui dolagui, Lapelole, etc. son lugares centrales en la historia de los qom. Al recorrer estos lugares en la actualidad resulta evidente que, cuando los qom hablan de ellos no buscan tan solo evocarlos sino actualizar y tratar de entender las complejas relaciones que ellos anudan.

Debido a su exposición llana y clara, Arte verbal qom resulta de manera general en una excelente aproximación a la lengua, historia y actualidad de los qom orientales y se constituye, a la vez, en un aporte significativo a los estudios de su lengua y de su arte verbal que la misma autora inició (Messineo 2004). Para los etnógrafos de la región, esta obra servirá de referencia para contrastar y proyectar los datos etnográficos propios. Para los americanistas en general, este libro brinda materiales de alta calidad etnográfica y potencialidad comparativa.

\section{BIBLIOGRAFÍA}

\section{CERIANI Cernadas y César CERIANI}

2008, « Vampiros en el Chaco. Rumor, Mito y Drama entre los Toba Orientales », Indiana, 25 (0), p. 27-49.

\section{MESSINEO Cristina}

2004, « Toba Discourse as Verbal Art », Anthropological linguistics, 46 (4), p. 450-479.

\section{WRIGHT Pablo}

1990, « NqataGako (advice): a Toba oral genre », Paper presented at the 90 th Meeting of the American Anthropological Association, November 20-24, Chicago, ms. inédito.

2008, Ser en el sueño. Crónicas de historia y vida toba, Biblos/Culturalia, Buenos Aires. 
AUTORES

EMILIO ROBLEDO

Doctorando en Ciencias Antropológicas Universidad Nacional de Córdoba, Becario SECYT-UNC 